\title{
Association of raisin consumption with nutrient intake, diet quality, and health risk factors in US adults: National Health and Nutrition Examination Survey 2001-2012
}

\author{
Victor L. Fulgoni III ${ }^{a}$, James Painter ${ }^{\mathrm{b}}$ and Arianna Carughic

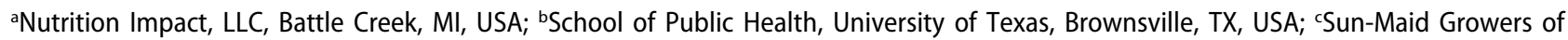 \\ California, Kingsburg, CA, USA
}

\begin{abstract}
Raisins are one of the most commonly consumed dried fruits. Because of their unique nutrient profile, raisins may have some distinctive health benefits. The purpose of this study was to examine the cross-sectional association between raisin consumption and nutrient intake, dietary quality, body weight, and metabolic syndrome risk factors in adults. Data from the National Health and Nutrition Examination Survey (NHANES), 2001-2012 ( $n=29,684$ ) were used. Raisin consumers ( $n=458,60 \%$ female) were defined as those having any amount of raisins during the first $24 \mathrm{~h}$ dietary recall. Diet quality was calculated using the Healthy Eating Index-2010 (HEI2010). Covariate (demographic and lifestyle)-adjusted regression analyses were conducted using appropriate sample weights and significance was set at $p<0.01$. Raisin consumers had higher intakes of energy (9\%); higher intakes of 'nutrients of public health concern/shortfall nutrients', such as dietary fiber (34\%), potassium (16\%), magnesium (22\%), vitamin C (24\%), and vitamin E (22\%); and lower intakes of 'nutrients to limit', such as added sugar $(-17 \%)$, saturated fat $(-15 \%)$, and sodium $(-10 \%)$, than non-consumers. No associations were observed for intakes of calcium, iron, vitamin $A$, vitamin $D$, and folate. Consumers had higher intakes of total fruit $(72 \%)$, whole fruit $(111 \%)$, vegetables (22\%), and whole grains (109\%), and had a higher diet quality, as indicated by $25 \%$ higher total HEl-2010 scores than non-consumers. Compared to non-consumers, raisin consumers had a lower body weight $(-4.2 \%)$, body mass index $(-5.2 \%)$, and waist circumference $(-3.8 \%)$, were $39 \%$ less likely to be overweight or obese, and had a $54 \%$ reduced risk of metabolic syndrome. In conclusion, raisin consumption was associated with better nutrient intake, diet quality, and weight parameters, and with lower risk of being obese and having metabolic syndrome in US adults.
\end{abstract}

\section{ARTICLE HISTORY}

Received 4 April 2017

Accepted 8 September 2017

\section{KEYWORDS}

NHANES; raisins; Healthy

Eating Index; body weight; BMI; obesity; metabolic syndrome

\section{Introduction}

Dietary guidelines around the world unequivocally recommend increased consumption of fruit and vegetables. The Dietary Guidelines for Americans (DGA) 2015-2020 also recommend the consumption of fruit and vegetables as part of a healthy eating pattern [1]. MyPlate (ChooseMyPlate.gov) indicates that half of the food on a meal plate should be fruit and vegetables and recommends 1.5-2 cups equivalent of fruit per day for adults, depending on age, gender, and physical activity [2]. Fruits are an important source of many essential nutrients, including potassium, dietary fiber, vitamin $\mathrm{C}$, and folate, and are naturally low in fat, sodium, and calories. Despite these recommendations, over $75 \%$ of adult females and $85 \%$ of adult males in the USA do not consume an adequate amount of fruit and only $12 \%$ of adult females and $6 \%$ of adult males consume the recommended daily servings of fruit [3]. The DGA identified vitamin $A$, vitamin $D$, vitamin $E$, folate, vitamin $\mathrm{C}$, calcium, iron (for certain age and gender groups), magnesium, potassium, and fiber as 'shortfall nutrients', since these nutrients are being consumed at levels below those recommended; and of these, vitamin $\mathrm{D}$, calcium, iron, potassium, and fiber are being underconsumed to the extent that may pose a public health concern and are thus described as 'nutrients of public health concern' [1].

Raisins are dried grapes and are one of the most commonly consumed dried fruits [4]. Raisins are

\footnotetext{
CONTACT Victor L. Fulgoni III vic3rd@aol.com E Nutrition Impact, LLC, 9725 D Drive North, Battle Creek, MI 49014, USA

Responsibilities

VLF and AC conceived the overall design of the study. VLF was responsible for the analysis; VLF, JP, and AC all reviewed the analysis and the data. VLF drafted the initial manuscript, which was edited and critically reviewed by JP and AC. All authors contributed equally to this manuscript and read the final version.

(c) 2017 The Author(s). Published by Informa UK Limited, trading as Taylor \& Francis Group.

This is an Open Access article distributed under the terms of the Creative Commons Attribution License (http://creativecommons.org/licenses/by/4.0/), which permits unrestricted use, distribution, and reproduction in any medium, provided the original work is properly cited.
} 
consumed across the globe, and because of their unique nutrient profile they may have some distinctive health benefits. Raisins are low-medium energy dense, and provide important minerals and dietary fiber including fructooligosaccharides. One snack serving (43 g) of raisins contributes $129 \mathrm{kcal}, 1.6 \mathrm{~g}$ dietary fiber, $0.2 \mathrm{~g}$ total fat, $25 \mathrm{~g}$ total sugar, $322 \mathrm{mg}$ potassium, $14 \mathrm{mg}$ magnesium, and $0.8 \mathrm{mg}$ iron [5]. Raisins also provide a wide variety of phytochemicals including flavonoids (catechins, kaempferol, quercetin, and rutin), hydrocinnamic acids (cafteric and coutaric acids), epicatechins, phytoestrogens (daidzein and genestein), and resveratrol [6,7]. The effects of raisin intake on blood pressure, lipid profile, glucose, postprandial glycemia/ insulinemia, oxidative damage, and satiety have been previously investigated in human intervention studies [7-15]. Epidemiological studies examining the effect of raisins on diet quality and markers of health are very limited. Intake of dried fruits including raisins and other dried fruits, as well as intake of grape products (grapes, grape, juice and raisins), was associated with a higher intake of key nutrients and healthier dietary patterns in two previous analyses of data from the National Health and Nutrition Examination Survey (NHANES), but neither specifically focused on raisins (although raisins were a large component of dried fruit in one study) $[4,16]$. Given that raisins were the predominant dried fruit consumed in the studies mentioned above, we wanted to assess whether the results were due specifically to raisin consumption. Thus, the purpose of this study was to examine the cross-sectional association between raisin consumption and nutrient intakes, diet quality, body weight, and metabolic syndrome risk factors in a nationally representative large sample of US adults.

\section{Methods}

\section{Subjects}

Data from What We Eat In America 2001-2012, the dietary intake component of the NHANES, were used to assess raisin intake [17]. NHANES is a continuous survey conducted by the National Center for Health Statistics (NCHS). The present analysis combined six NHANES data sets (NHANES 2001-2002, 2003-2004, 2005-2006, 2007-2008, 2009-2010, and 2011-2012). Adults aged 19 years and older $(n=29,684)$ with reliable $24 \mathrm{~h}$ dietary recall interviews were included. Pregnant and/or lactating females and those with incomplete or unreliable $24 \mathrm{~h}$ recall data were excluded. All participants provided written informed consent and the Research Ethics Review Board at the
NCHS approved the survey protocol. Dietary intake data were obtained using the United States Department of Agriculture's (USDA's) automated multiple-pass method [17] in the Mobile Examination Center. Data were collected to represent all days of the week and food models were used to help with portion size determination. For these analyses, only subjects with reliable $24 \mathrm{~h}$ dietary recall interviews (day 1 data only) as determined by USDA staff were used.

\section{Estimation of intake}

Raisin intakes were assessed using two USDA food codes for raisins [18]: plain raisins (USDA food code 62125100 ) and cooked raisins (USDA food code 62125110). Raisin consumers $(n=458)$ were defined as those consuming any amount of raisins during the first $24 \mathrm{~h}$ recall. Energy and nutrient intake were determined using the USDA Nutrient Database for Standard Reference Releases [19] in conjunction with the respective Food and Nutrient Database for Dietary Studies for participants in each NHANES cycle [18]. The USDA MyPyramid Equivalents Database (MPED) and Food Patterns Equivalents Database (FPED) were used to calculate intake as MyPlate [20,21] servings. The MPED and FPED translate dietary recall data into equivalent servings of the MyPlate major food groups and corresponding subgroups. The number of MyPlate servings was aggregated over all foods consumed during the $24 \mathrm{~h}$ recall to calculate the MyPlate food group intakes per day.

\section{Estimation of diet quality}

Diet quality was calculated using the Healthy Eating Index-2010 (HEI-2010). HEI-2010 has 12 components, each representing a different aspect of diet quality [22]. Nine component scores, namely total fruit, whole fruit, total vegetables, greens and beans, whole grains, dairy, total protein foods, seafood and plant proteins, and fatty acid ratio, measure adequacy and a higher score indicates higher consumption; three component scores, namely refined grains, sodium, and empty calories, measure moderation items and higher scores indicate lower consumption. Scores on many of the HEI components are based on intake per $1000 \mathrm{kcal}$, so higher scores cannot be achieved just by eating more of everything. HEI-2010 scores were estimated using day 1 dietary intake data. The SAS code used to calculate HEI-2010 scores was downloaded from the USDA website [23]. 


\section{Estimation of physiological markers of risk}

Health indices evaluated included body weight, body mass index (BMI), waist circumference, skinfold thickness, blood pressure (BP), fasting plasma glucose, fasting plasma insulin, homeostatic model assessment of insulin resistance (HOMA-IR), C-reactive protein (CRP), fasting triglycerides, total cholesterol, low-density lipoprotein (LDL)-cholesterol (fasting), high-density lipoprotein (HDL)-cholesterol, and homocysteine, using NHANES standard protocols [17]. For a variety of reasons, not all individuals have values for all tests (see tables for sample numbers). Risk factors for physiological variables were defined as obesity (BMI $\geq 30 \mathrm{~kg} / \mathrm{m}^{2}$ ), overweight (BMI $\left.25-29.9 \mathrm{~kg} / \mathrm{m}^{2}\right)$, elevated waist circumference $(>102 \mathrm{~cm}$ for males and $>88 \mathrm{~cm}$ for females); elevated BP (systolic $\mathrm{BP} \geq 130 \mathrm{mmHg}$ or diastolic $\mathrm{BP} \geq 85 \mathrm{mmHg}$ ); elevated total cholesterol $(\geq 200 \mathrm{mg} / \mathrm{dL}$ ), reduced HDL-cholesterol $(<40 \mathrm{mg} / \mathrm{dL}$ for males and $<50 \mathrm{mg} / \mathrm{dL}$ for females); elevated LDL-cholesterol $(\geq 100 \mathrm{mg} / \mathrm{dL})$, elevated triglycerides $(\geq 150 \mathrm{mg} / \mathrm{dL}$ ); elevated CRP ( $\geq 6.0 \mathrm{mg} / \mathrm{dL}$ ); elevated glucose (fasting glucose $\geq 110 \mathrm{mg} / \mathrm{dL}$ ); elevated insulin; elevated HOMA-IR ( $\geq 4.0$ ); and metabolic syndrome (NHLBI Adult Treatment Panel III criteria, namely having three or more of the following risk factors: elevated waist circumference, elevated BP or taking medication, reduced HDL-cholesterol, elevated triglycerides, and elevated glucose or taking medication) [24-26].

\section{Statistical analysis}

Least square means (LSMs) and standard errors (SEs) were determined for energy and nutrient intakes, food group intake, diet quality, and physiological markers of metabolic disease risk in raisin consumers and non-consumers via regression analyses. The data were adjusted for the complex sample design of NHANES using appropriate survey weights, strata, and primary sampling units. To account for NHANES national probability sampling and to ensure that estimates remain nationally representative, sample weights must be used in all analyses: day 1 dietary weights were used in all intake analyses, while the Mobile Examination Center weights were used for physiological variables except where the outcome was a fasting laboratory variable, in which case fasting subsample weights were used. Food group/nutrient intakes were adjusted for age, gender, ethnicity, poverty-income ratio, physical activity level, current smoking status, alcohol intake, and energy intake (except for energy intake). Diet quality was adjusted for the same covariates but without energy intake, as HEI scores are already adjusted for energy intake. Physiological variables were adjusted for age, gender, ethnicity, poverty-income ratio, self-reported physical activity level (categorized as sedentary, moderate, or vigorous based on responses to questions on activity), current smoking status, alcohol intake, and BMI (for non-weight-related variables). Logistic regression was used to assess the association of raisin consumption with elevated/reduced risk of various health-related parameters; covariates for these analyses were similar to those for physiological variables. SAS 9.2 (SAS Institute, Cary, NC, USA) and SUDAAN 11 (RTI, Research Triangle Park, NC, USA) were used for all analyses. Data are presented as LSM \pm SE and significance was set at $p<0.01$.

\section{Results}

Approximately $1.76 \%$ of adults $(2.08 \%$ of females and $1.41 \%$ of males) aged 19 years and older $(n=458,60 \%$ female) were raisin consumers. The amount of raisins consumed was $32.5 \pm 1.9 \mathrm{~g} /$ day for both genders combined and $26.3 \pm 2.2 \mathrm{~g} /$ day and $41.8 \pm 3.6 \mathrm{~g} /$ day for females and males, respectively. Raisin consumers were more likely to be older and non-Hispanic white, and to have a higher income; and less likely to be male, Mexican American, and smokers, and to have a sedentary lifestyle compared to non-consumers (Table 1).

There were significant differences in nutrient intakes between the raisin consumers and the non-consumers (Table 2). Compared to non-consumers, raisin consumers had significantly higher $(p<0.01)$ intakes of calories (8.8\%), and energy-adjusted daily intakes of carbohydrate $(7.8 \%)$, dietary fiber $(34.0 \%)$, total sugar $(11.3 \%)$, copper $(20.3 \%)$, magnesium $(22.4 \%)$, potassium (15.7\%), $\beta$-carotene (51.2\%), vitamin C (23.6\%), vitamin $\mathrm{E}(22.0 \%)$, and vitamin $\mathrm{K}(52.9 \%)$. Adult raisin consumers also had significantly lower $(p<0.01)$

Table 1. Characteristics of adult raisin consumers, National Health and Nutrition Examination Survey (NHANES) 2001-2012.

\begin{tabular}{lccc}
\hline Variables & Non-consumers & Consumers & $p^{\mathrm{a}}$ \\
\hline Sample (n) & 29,226 & 458 & \\
Age (years) & $46.4 \pm 0.3$ & $54.1 \pm 1.2$ & $<0.0001$ \\
Gender & & & \\
$\quad$ Male (\%) & $49.4 \pm 0.3$ & $39.9 \pm 3.2$ & 0.0033 \\
Race/ethnicity & & & \\
$\quad$ Mexican American (\%) & $7.94 \pm 0.66$ & $3.78 \pm 0.99$ & 0.0005 \\
$\quad$ Other Hispanic (\%) & $4.66 \pm 0.50$ & $3.69 \pm 0.67$ & 0.2459 \\
$\quad$ Non-Hispanic white (\%) & $70.3 \pm 1.4$ & $81.5 \pm 2.1$ & $<0.0001$ \\
$\quad$ Non-Hispanic black (\%) & $11.4 \pm 0.8$ & $7.87 \pm 1.28$ & 0.0165 \\
$\quad$ Other (\%) & $5.66 \pm 0.32$ & $3.14 \pm 1.02$ & 0.0186 \\
Poverty-income ratio & $2.97 \pm 0.03$ & $3.44 \pm 0.12$ & 0.0003 \\
Smoker (\%) & $24.0 \pm 0.5$ & $8.18 \pm 1.88$ & $<0.0001$ \\
Physical activity & & & \\
$\quad$ Sedentary (\%) & $27.7 \pm 0.6$ & $19.6 \pm 2.1$ & 0.0002 \\
$\quad$ Moderate (\%) & $34.9 \pm 0.4$ & $39.5 \pm 4.1$ & 0.2657 \\
$\quad$ Vigorous (\%) & $37.4 \pm 0.7$ & $40.9 \pm 3.8$ & 0.3584 \\
\hline
\end{tabular}

Data are shown as mean $\pm \mathrm{SE}$.

${ }^{\mathrm{a}} p$ value for difference between raisin consumers and non-consumers. 
Table 2. Energy and nutrient intakes in adult raisin consumers ( $n=458)$ and non-consumers ( $n=29,226)$ : National Health and Nutrition Examination Survey (NHANES) 2001-2012, gendercombined data.

\begin{tabular}{|c|c|c|c|}
\hline Variables $^{\mathrm{a}}$ & Non-consumers & Consumers & $p^{\mathrm{b}}$ \\
\hline Energy (kcal) & $2074 \pm 9$ & $2257 \pm 44$ & 0.0001 \\
\hline Protein $(\mathrm{g})$ & $82.2 \pm 0.3$ & $81.0 \pm 1.5$ & 0.4176 \\
\hline Carbohydrate (g) & $261 \pm 1$ & $282 \pm 4$ & $<0.0001$ \\
\hline Dietary fiber (g) & $16.5 \pm 0.1$ & $22.1 \pm 0.8$ & $<0.0001$ \\
\hline Total sugars (g) & $116 \pm 1$ & $129 \pm 4$ & 0.0011 \\
\hline Added sugars (tsp) & $18.0 \pm 0.2$ & $14.9 \pm 0.7$ & 0.0001 \\
\hline Total fat $(\mathrm{g})$ & $78.0 \pm 0.3$ & $72.1 \pm 1.6$ & 0.0004 \\
\hline MUFA (g) & $28.8 \pm 0.1$ & $26.3 \pm 0.7$ & 0.0005 \\
\hline PUFA (g) & $17.3 \pm 0.1$ & $18.1 \pm 0.6$ & 0.1921 \\
\hline SFA $(\mathrm{g})$ & $25.0 \pm 0.1$ & $21.3 \pm 0.9$ & $<0.0001$ \\
\hline Cholesterol (mg) & $298 \pm 2$ & $231 \pm 11$ & $<0.0001$ \\
\hline Calcium (mg) & $861 \pm 6$ & $886 \pm 28$ & 0.4032 \\
\hline Copper (mg) & $1.33 \pm 0.02$ & $1.60 \pm 0.05$ & $<0.0001$ \\
\hline Iron (mg) & $15.1 \pm 0.2$ & $16.2 \pm 0.4$ & 0.0106 \\
\hline Magnesium (mg) & $290 \pm 1$ & $355 \pm 11$ & $<0.0001$ \\
\hline Phosphorus (mg) & $1312 \pm 5$ & $1364 \pm 27$ & 0.0657 \\
\hline Potassium (mg) & $2665 \pm 10$ & $3084 \pm 77$ & $<0.0001$ \\
\hline Selenium $(\mu \mathrm{g})$ & $112 \pm 1$ & $106 \pm 3$ & 0.0363 \\
\hline Sodium (mg) & $3541 \pm 17$ & $3190 \pm 78$ & $<0.0001$ \\
\hline Zinc (mg) & $11.7 \pm 0.2$ & $11.6 \pm 0.4$ & 0.9154 \\
\hline Vitamin A $(\mu \mathrm{g})$ & $589 \pm 12$ & $653 \pm 36$ & 0.0939 \\
\hline$\beta$-Carotene $(\mu \mathrm{g})$ & $2119 \pm 50$ & $3204 \pm 340$ & 0.0025 \\
\hline Thiamin (mg) & $1.59 \pm 0.02$ & $1.62 \pm 0.05$ & 0.5114 \\
\hline Riboflavin (mg) & $2.03 \pm 0.03$ & $2.04 \pm 0.07$ & 0.8993 \\
\hline Niacin $(\mathrm{mg})$ & $24.4 \pm 0.1$ & $24.4 \pm 0.6$ & 0.9967 \\
\hline Total folate $(\mu \mathrm{g})$ & $405 \pm 3$ & $432 \pm 14$ & 0.0648 \\
\hline Vitamin $B_{6}(\mathrm{mg})$ & $1.98 \pm 0.03$ & $2.12 \pm 0.08$ & 0.0972 \\
\hline Vitamin $B_{12}(\mu \mathrm{g})$ & $5.21 \pm 0.18$ & $4.48 \pm 0.30$ & 0.0114 \\
\hline Vitamin C (mg) & $94.4 \pm 1.2$ & $117 \pm 8$ & 0.0081 \\
\hline Vitamin D $(\mu \mathrm{g})$ & $4.45 \pm 0.15$ & $4.06 \pm 0.34$ & 0.2297 \\
\hline Vitamin E (mg) & $7.31 \pm 0.12$ & $8.92 \pm 0.47$ & 0.0007 \\
\hline Vitamin $\mathrm{K}(\mu \mathrm{g})$ & $102 \pm 2$ & $156 \pm 19$ & 0.0073 \\
\hline
\end{tabular}

Data are shown as least square mean $\pm \mathrm{SE}$.

alues were adjusted for age, gender, ethnicity, poverty-income ratio, physical activity level, current smoking status, alcohol, and energy intake (except for energy).

${ }^{b} p$ value for difference between raisin consumers and non-consumers. MUFA, monounsaturated fatty acids; PUFA, polyunsaturated fatty acids; SFA, saturated fatty acids.

intakes of added sugar $(-17.1 \%)$, total fat $(-7.6 \%)$, monounsaturated fatty acids (MUFA) $(-8.7 \%)$, saturated fatty acids (SFA) (-14.8\%), cholesterol $(-22.4 \%)$, and sodium $(-9.9 \%)$ compared to non-consumers. The intake of other nutrients was not significantly different between raisin consumers and nonconsumers (Table 2).

Intake of raisins was also associated with significant differences $(p<0.01)$ in specific MyPlate food groups (Table 3). Significantly higher intakes of total fruit (72.1\%), whole fruit (112\%), total vegetable (21.9\%), and whole grain (109\%) were observed among adults consuming raisins compared to non-consumers. Raisin intake was also associated with a significantly better overall diet quality among consumers, as indicated by their $25.1 \%$ higher HEI-2010 total score $(61.4 \pm 1.0$ vs $49.1 \pm 0.2$ points, $p<0.0001)$ compared to those not consuming raisins (Table 4). Raisin consumers also had higher $(p<0.01)$ HEI-2010 component scores for total vegetables (11.8\%),
Table 3. Intake of MyPlate food groups in adult raisin consumers $(n=458)$ and non-consumers ( $n=29,226)$ : National Health and Nutrition Examination Survey (NHANES) 2001-2012, gender-combined data.

\begin{tabular}{lccc}
\hline Variables $^{\mathrm{a}}$ & Non-consumers & Consumers & $p^{\mathrm{b}}$ \\
\hline Total fruit (cup eq.) & $1.07 \pm 0.04$ & $1.84 \pm 0.11$ & $<0.0001$ \\
$\quad$ Whole fruit (cup eq.) & $0.66 \pm 0.03$ & $1.39 \pm 0.10$ & $<0.0001$ \\
Total vegetable (cup eq.) & $1.54 \pm 0.03$ & $1.88 \pm 0.10$ & 0.0005 \\
Total grain (oz eq.) & $6.73 \pm 0.09$ & $6.66 \pm 0.21$ & 0.7669 \\
$\quad$ Whole grain (oz eq.) & $0.70 \pm 0.04$ & $1.47 \pm 0.10$ & $<0.0001$ \\
Total dairy (cup eq.) & $1.36 \pm 0.05$ & $1.38 \pm 0.09$ & 0.8195 \\
Total protein group (oz eq.) & $6.27 \pm 0.11$ & $6.14 \pm 0.24$ & 0.5817 \\
\hline
\end{tabular}

Data are shown as least square mean $\pm \mathrm{SE}$.

aalues were adjusted for age, gender, ethnicity, poverty-income ratio, physical activity level, current smoking status, alcohol, and energy (kcal).

${ }^{b} p$ value for difference between raisin consumers and non-consumers.

greens and beans (40.9\%), total fruit (56.7\%), whole fruit $(83.0 \%)$, whole grain $(102 \%)$, seafood and protein $(44.4 \%)$, sodium (30.8\%), refined grains (16.0\%), and calories from solid fats, alcohol, and added sugars (SoFAAS) (18.7\%) compared to non-consumers (Table 4).

Adult raisin consumers had slightly but significantly lower body weight $(-4.2 \%, p=0.0056)$, BMI $(-5.2 \%$, $p=0.0004)$, and waist circumference $(-3.8 \%, p=0.0003)$ compared to non-consumers (Table 5). There were no significant differences in physiological laboratory measures (systolic BP, diastolic BP, total cholesterol, LDL-cholesterol, HDL-cholesterol, triglycerides, CRP, plasma glucose, insulin, or HOMA-IR) associated with raisin consumption

Table 4. Healthy Eating Index-2010 (HEl-2010) total score and component scores of adult raisin consumers $(n=458)$ and nonconsumers ( $n=29,226)$ : National Health and Nutrition Examination Survey (NHANES) 2001-2012, gender-combined data.

\begin{tabular}{|c|c|c|c|}
\hline Variables $^{\mathrm{a}}$ & Non-consumers & Consumers & $p^{b}$ \\
\hline HEl-2010 total score & $49.07 \pm 0.20$ & $61.40 \pm 0.97$ & $<0.0001$ \\
\hline $\begin{array}{l}\text { Component } 1 \text { (total } \\
\text { vegetables) }\end{array}$ & $3.09 \pm 0.02$ & $3.45 \pm 0.11$ & 0.0017 \\
\hline $\begin{array}{l}\text { Component } 2 \text { (greens \& } \\
\text { beans) }\end{array}$ & $1.37 \pm 0.03$ & $1.93 \pm 0.17$ & 0.0013 \\
\hline Component 3 (total fruit) & $2.31 \pm 0.03$ & $3.62 \pm 0.11$ & $<0.0001$ \\
\hline Component 4 (whole fruit) & $2.09 \pm 0.03$ & $3.83 \pm 0.09$ & $<0.0001$ \\
\hline $\begin{array}{l}\text { Component } 5 \text { (whole } \\
\text { grains) }\end{array}$ & $2.08 \pm 0.04$ & $4.21 \pm 0.20$ & $<0.0001$ \\
\hline Component 6 (dairy) & $4.41 \pm 0.04$ & $4.58 \pm 0.25$ & 0.5022 \\
\hline $\begin{array}{l}\text { Component } 7 \text { (total } \\
\text { protein foods) }\end{array}$ & $4.31 \pm 0.02$ & $4.22 \pm 0.08$ & 0.3107 \\
\hline $\begin{array}{l}\text { Component } 8 \text { (seafood \& } \\
\text { plant protein) }\end{array}$ & $1.99 \pm 0.03$ & $2.87 \pm 0.17$ & $<0.0001$ \\
\hline $\begin{array}{l}\text { Component } 9 \text { (fatty acid } \\
\text { ratio) }\end{array}$ & $5.39 \pm 0.05$ & $6.17 \pm 0.31$ & 0.0112 \\
\hline Component 10 (sodium) & $4.25 \pm 0.05$ & $5.56 \pm 0.27$ & $<0.0001$ \\
\hline $\begin{array}{l}\text { Component } 11 \text { (refined } \\
\text { grains) }\end{array}$ & $5.72 \pm 0.04$ & $6.64 \pm 0.25$ & 0.0004 \\
\hline $\begin{array}{l}\text { Component } 12 \text { (SoFAAS } \\
\text { calories) }\end{array}$ & $12.06 \pm 0.11$ & $14.31 \pm 0.38$ & $<0.0001$ \\
\hline
\end{tabular}

Data are shown as least square mean $\pm \mathrm{SE}$.

aValues were adjusted for age, gender, ethnicity, poverty-income ratio, physical activity level, current smoking status, and alcohol.

${ }^{b} p$ value for difference between raisin consumers and non-consumers.

SoFAAS, solid fats, alcohol, and added sugars. 
Table 5. Association of raisin consumption with anthropometric and physiological variables in adults: National Health and Nutrition Examination Survey (NHANES) 2001-2012, gender-combined data.

\begin{tabular}{|c|c|c|c|c|}
\hline Variables $^{\mathrm{a}}$ & $n$ & Non-consumers & Consumers & $p^{b}$ \\
\hline \multicolumn{5}{|l|}{ Anthropometric variables } \\
\hline Body weight $(\mathrm{kg})$ & 29,255 & $79.8 \pm 0.3$ & $76.4 \pm 1.2$ & 0.0056 \\
\hline Body mass index $\left(\mathrm{kg} / \mathrm{m}^{2}\right)$ & 29,115 & $28.8 \pm 0.1$ & $27.3 \pm 0.4$ & 0.0004 \\
\hline Waist circumference $(\mathrm{cm})$ & 28,519 & $97.8 \pm 0.2$ & $94.1 \pm 1.0$ & 0.0003 \\
\hline Triceps skinfold thickness (mm) & 22,355 & $19.2 \pm 0.1$ & $17.8 \pm 0.6$ & 0.0157 \\
\hline Waist to height ratio & 28,410 & $0.59 \pm 0.004$ & $0.56 \pm 0.01$ & 0.0001 \\
\hline \multicolumn{5}{|l|}{ Physiological laboratory variables } \\
\hline Diastolic blood pressure $(\mathrm{mmHg})$ & 28,496 & $71.3 \pm 0.2$ & $71.4 \pm 0.7$ & 0.9949 \\
\hline Systolic blood pressure $(\mathrm{mmHg})$ & 28,615 & $125 \pm 0.3$ & $123 \pm 1$ & 0.1623 \\
\hline Total cholesterol (mg/dL) & 28,076 & $199 \pm 1$ & $198 \pm 3$ & 0.9010 \\
\hline LDL-cholesterol (mg/dL) & 13,306 & $117 \pm 1$ & $115 \pm 3$ & 0.3731 \\
\hline HDL-cholesterol (mg/dL) & 28,075 & $52.3 \pm 0.2$ & $54.4 \pm 1.7$ & 0.2315 \\
\hline Triglyceride $(\mathrm{mg} / \mathrm{dL})$ & 13,772 & $140 \pm 2$ & $131 \pm 6$ & 0.0951 \\
\hline $\mathrm{CRP}(\mathrm{mg} / \mathrm{dL})$ & 23,604 & $0.43 \pm 0.01$ & $0.37 \pm 0.47$ & 0.1694 \\
\hline Plasma glucose (mg/dL) & 13,903 & $107 \pm 1$ & $104 \pm 1.5$ & 0.0191 \\
\hline Insulin $(\mu \mathrm{U} / \mathrm{mL})$ & 13,639 & $12.6 \pm 0.2$ & $11.8 \pm 0.5$ & 0.0714 \\
\hline HOMA-IR & 13,618 & $3.52 \pm 0.06$ & $3.20 \pm 0.15$ & 0.0335 \\
\hline
\end{tabular}

Data are shown as least square mean $\pm \mathrm{SE}$.

${ }^{a}$ Values were adjusted for age, gender, ethnicity, poverty-income ratio, physical activity level, current smoking status, alcohol, and BMI (only for variables not related to weight).

${ }^{\mathrm{b}} p$ value for difference between raisin consumers and non-consumers.

LDL, low-density lipoprotein; HDL, high-density lipoprotein; CRP, C-reactive protein; HOMA-IR, homeostatic model assessment of insulin resistance.

in adults (Table 5). The differences between consumers and non-consumers remained non-significant for these physiological variables $(p>0.01)$ when the data were further analyzed separately for males and females (data not presented).

Consumption of raisins was also associated with a $37 \%$ reduced risk of being overweight [odds ratio $(\mathrm{OR})=0.63,99 \%$ confidence interval $(\mathrm{CI})$ 0.42, 0.95; $p=0.0037], 43 \%$ reduced risk of being obese $(\mathrm{OR}=0.57,99 \%$ CI $0.35,0.93 ; p=0.0032), 39 \%$ reduced risk of being overweight or obese $(\mathrm{OR}=0.61,99 \%$ CI $0.41,0.89 ; p=0.0009), 48 \%$ reduced risk of having an elevated waist circumference $(\mathrm{OR}=0.52,99 \%$ CI $0.36,0.74 ; p<0.0001), 95 \%$ reduced risk of having elevated CRP (OR $=0.05,99 \%$ CI $0.01,0.34 ; p<0.0001$ ), and $54 \%$ reduced risk of metabolic syndrome $(\mathrm{OR}=0.46,99 \% \mathrm{CI} 0.26,0.82$; $p=0.0005)$. The odds ratios of other health-related conditions were similar $(p>0.01)$ for raisin consumers compared to non-consumers (Table 6) and remained similar when data were further analyzed for males and females separately (data not presented).

\section{Discussion}

This is the first report to specifically investigate raisin (plain or cooked) consumption in the US population and to explore its cross-sectional relationships with nutrient intake, diet quality, and physiological markers of health using a large national representative sample of US adults. In the present study, we combined data from six recent NHANES cycles, and the combined data set provided a sample size of over 29,000 adults.
The NHANES 2001-2012 data showed that 1.5\% of the adult US population consumed raisins on the day of the recall and raisin consumption was associated with better nutrient intake, diet quality, and weight and metabolic syndrome parameters.

Adult consumers of raisins consumed significantly more calories and carbohydrate but less fat compared to their respective non-consumers. In addition, they consumed more energy-adjusted dietary fiber, copper, magnesium, potassium, $\beta$-carotene, vitamin $C$, vitamin $\mathrm{E}$, and vitamin $\mathrm{K}$ compared to non-consumers. A recent analysis of NHANES 2003-2008 also reported higher intake of several key nutrients including dietary fiber, vitamin A, vitamin $\mathrm{C}$, calcium, magnesium, and potassium among consumers of grape products (fruit, juice, and raisins) compared to non-consumers [16]. Higher intakes of most vitamins and minerals were also reported for consumers of dried fruits compared to non-consumers in an earlier analysis of NHANES 1994-2004 [4]. Most of these nutrients (fiber, magnesium, potassium, vitamin $\mathrm{C}$, and vitamin E) are currently underconsumed and are identified as 'shortfall nutrients' by the DGA [1]. In addition, the current intakes of fiber and potassium are low to the extent that they may pose a public health concern and therefore are termed 'nutrients of public health concern' by the DGA [1]. Less than $5 \%$ of the population is currently consuming more than the adequate intake of dietary fiber or potassium [1]. The DGA indicates that the low intakes of dietary fiber and potassium are due to low intakes of fruit and vegetables, and recommends eating more fruit and vegetables along with whole grain and dairy to increase intakes of fiber 
underreporting of energy intake by raisin consumers and non-consumers, and also that raisin consumption may just be a marker for those who lead a healthier lifestyle (e.g., less sedentary behavior).

Raisin intake was not associated with many physiological measurements, including BP, blood lipids, or blood sugar/insulin in the present analysis. Human intervention studies have reported mixed results on the effects of raisins on BP [9-11]. Raisin intake did not affect the lipid profile of fasting glucose or insulin in clinical studies [9-11]. However, raisins have consistently been demonstrated to lower postprandial glycemia and/or insulinemia in acute human feeding studies with healthy and diabetic subjects [10-13]. Raisins are high in fructose, which has a low glycemic index [13]. Although there were no differences in levels of CRP between consumers and non-consumers, the raisin consumers had a significantly reduced risk of having elevated CRP (OR $=0.05, p<0.0001)$ in the present study. CRP is a sensitive marker of inflammation, and elevated levels have been associated with the risk of coronary artery disease and metabolic syndrome $[39,40]$. Raisin consumers were also at a $54 \%$ lower risk of metabolic syndrome.

Overall, it is not surprising that the intake of added sugars was lower in raisin consumers as it is likely that raisins replaced other sources of sugars and added sugars in the diet. The higher intakes of total vegetables and whole grains, along with the lower intakes of saturated fats and sodium (and the lower smoking rates and less sedentary behavior) support the concept that the raisin consumption is a marker for a healthier lifestyle.

\section{Strengths and limitations}

A limitation of this study is that cross-sectional studies cannot be used to determine cause and effect. In addition, $24 \mathrm{~h}$ dietary recalls rely on participants' memory to self-report dietary intakes and are subject to misreporting. Also, the data used in this study were based on a single $24 \mathrm{~h}$ dietary recall and may not represent usual intake; that said, linking a single dietary recall to physiological measurements should bias results to the null. Strengths of this study include the use of large nationally representative sample achieved through combining several sets of NHANES data releases, and the use of numerous covariates to adjust data to remove potential confounding. The researchers, however, acknowledge that residual confounding may still exist that could explain some of the results reported.

\section{Conclusion}

The results of this study suggest that raisin consumption is associated with better nutrient intake, diet quality, and weight parameters, and with lowered risk of obesity and metabolic syndrome in US adults, and may be a marker for those who lead a healthier lifestyle.

\section{Disclosure statement}

JP consults with Sun-Maid Raisin Growers of California, Paramount Pistachios, the National Pasteurized Egg Board, and the National Dairy Council. AC consults for Sun-Maid Raisin Growers of California. VLF provides database analyses for numerous members of the food and beverage industry.

\section{Funding}

Funding for this study was received from Sun-Maid Raisin Growers of California.

\section{References}

[1] US Department of Health and Human Services and US Department of Agriculture. 2015-2020 Dietary Guidelines for Americans. 8th ed. Dec 2015. Available from: http:// health.gov/dietaryguidelines/2015/guidelines/

[2] USDA. All about the fruit group; 2010. Available from: https://www.choosemyplate.gov/fruit

[3] National Cancer Institute. Usual dietary intakes: recommended amounts of total fruits table; 2014[cited 2015 Apr 1]. Available from: http://appliedresearch.cancer. gov/diet/usualintakes/pop/2007-10/table_b01.html

[4] Keast DR, O’Neil CE, Jones JM. Dried fruit consumption is associated with improved diet quality and reduced obesity in US adults: National Health and Nutrition Examination Survey, 1999-2004. Nutr Res. 2011;31:460-467.

[5] United States Department of Agriculture, Agriculture Research Service. USDA National nutrient database for standard reference, release 28. [cited 2016 Oct 18]. Available from: https://ndb.nal.usda.gov/ndb/foods/ show $/ 2371$ ? fgcd $=\&$ manu $=\&$ lfacet $=\&$ format $=\&$ count $=$ $\& \max =35 \&$ offset $=\&$ sort $=\&$ qlookup $=$ raisins

[6] Karadeniz F, Durst RW, Wrolstad RE. Polyphenolic composition of raisins. J Agric Food Chem. 2000;48:5343-5350.

[7] Williamson G, Carughi A. Polyphenol content and health benefits of raisins. Nutr Res. 2010;30:511-519.

[8] Anderson JW, Waters AR. Raisin consumption by humans: effects on glycemia and insulinemia and cardiovascular risk factors. J Food Sci. 2013;78 Suppl 1:A11-7.

[9] Kanellos PT, Kaliora AC, Tentolouris NK, et al. A pilot, randomized controlled trial to examine the health outcomes of raisin consumption in patients with diabetes. Nutrition. 2014;30:358-364.

[10] Anderson JW, Weiter KM, Christian AL, et al. Raisins compared with other snack effects on glycemia and blood pressure: a randomized, controlled trial. Postgrad Med. 2014;126:37-43. 
[11] Bays H, Weiter K, Anderson J. A randomized study of raisins versus alternative snacks on glycemic control and other cardiovascular risk factors in patients with type 2 diabetes mellitus. Phys Sportsmed. 2015;43:37-43.

[12] Kanellos PT, Kaliora AC, Liaskos C, et al. A study of glycemic response to Corinthian raisins in healthy subjects and in type 2 diabetes mellitus patients. Plant Foods Hum Nutr. 2013;68:145-148.

[13] Esfahani A, Lam J, Kendall CW. Acute effects of raisin consumption on glucose and insulin reponses in healthy individuals. J Nutr Sci. 2014;3:1-6.

[14] Patel BP, Luhovyy B, Mollard R, et al. A premeal snack of raisins decreases mealtime food intake more than grapes in young children. Appl Physiol Nutr Metab. 2013;38:382-389.

[15] Patel BP, Bellissimo N, Luhovyy B, et al. An after-school snack of raisins lowers cumulative food intake in young children. J Food Sci. 2013;78 Suppl 1:A5-A10.

[16] McGill CR, Keast DR, Painter JE, et al. Improved diet quality and increased nutrient intakes associated with grape product consumption by U.S. children and adults: National Health and Nutrition Examination Survey 2003 to 2008. J Food Sci. 2013;78 Suppl 1:A1-A4.

[17] Centers for Disease Control and Prevention (CDC), National Center for Health Statistics. National Health and Nutrition Examination Survey. Hyattsville (MD): National Center for Health Statistics; [cited 2015 Sep 28]. Available from: http://www.cdc.gov/nchs/nhanes/ about_nhanes.htm

[18] USDA, Agricultural Research Service. Food surveys research group: food and nutrient database for dietary studies; [cited 2015 Sep 28]. Available from: https:// www.ars.usda.gov/northeast-area/beltsville-md/belts ville-human-nutrition-research-center/food-surveysresearch-group/docs/fndds/

[19] US Department of Agriculture, Agricultural Research Service. USDA national nutrient database for standard reference; [cited 2015 Sep 28]. Available from: https:// www.ars.usda.gov/northeast-area/beltsville-md/belts ville-human-nutrition-research-center/nutrient-datalaboratory/docs/usda-national-nutrient-database-forstandard-reference/

[20] Bowman SA, Friday JE, Moshfegh A MyPyramid equivalents database. Food surveys research group web site: USDA Agricultural Research Service; 2008 [cited 2015 Sep 28]. Available from: http://www.ars.usda.gov/ Services/docs.htm?docid $=17565$

[21] US Department of Agriculture, Agricultural Research Service. USDA food patterns equivalent database; [cited 2015 Sept 28]. Available from: https://www.ars. usda.gov/northeast-area/beltsville-md/beltsville-humannutrition-research-center/food-surveys-research-group/ docs/fped-databases/

[22] Guenther PM, Casavale KO, Reedy J, et al. Update of the Healthy Eating Index: HEI-2010. J Acad Nutr Diet. 2013;113:569-580.

[23] National Cancer Institute. Healthy Eating Index. HEI tools for researchers. (updated April 2014). [cited 2015 Sep 28]. Available from: http://appliedresearch.cancer. gov/hei/tools.html

[24] National Cholesterol Education Program: National Heart, Lung, and Blood Institute. Detection, evaluation, and treatment of high blood cholesterol in adults (Adult Treatment Panel III). 2002. NIH Publication No. 02-5215. Bethesda, MD: National Heart, Lung, and Blood Institute.

[25] National Institutes of Health: National Heart, Lung, and Blood Institute. Clinical guidelines on the identification, evaluation, and treatment of overweight and obesity in adults; [cited 2015 Sep 28]. Available from: http://www. nhlbi.nih.gov/guidelines/obesity/ob_gdlns.pdf

[26] Matthews DR, Hosker JP, Rudenski AS, et al. Homeostasis model assessment: insulin resistance and beta-cell function from fasting plasma glucose and insulin concentrations in man. Diabetologia. 1985 Jul;28(7):412-419.

[27] Hiza HA, Casavale KO, Guenther PM, et al. Diet quality of Americans differs by age, sex, race/ethnicity, income, and education level. J Acad Nutr Diet. 2013;113:297-306.

[28] Reedy J, Krebs-Smith SM, Bosire C. Evaluating the food environment: application of the Healthy Eating Index2005. Am J Prev Med. 2010;38:465-471.

[29] Juan WY, Guenther PM, Kott PS. Nutrition insight 41. Alexandria: United States Department of Agriculture Center for Nutrition Policy and Promotion; 2008. Diet quality of older Americans in 1994-96 and 2001-02 as measured by the Healthy Eating Index-2005.

[30] Fulgoni VL, Keast DR, Drewnowski A. Development and validation of the Nutrient-rich Foods Index: a tool to measure nutritional quality of foods. J Nutr. 2009;139:1549-1554.

[31] Nicklas TA, O’Neil CE, Fulgoni VL. Diet quality is inversely related to cardiovascular risk factors in adults. J Nutr. 2012;142:2112-2118.

[32] Chiuve S, Fung T, Rimm E, et al. Alternative dietary indices both strongly predict risk of chronic disease. J Nutr. 2012;142:1009-1018.

[33] Reedy J, Mitrou PN, Krebs-Smith SM, et al. Index-based dietary patterns and risk of colorectal cancer: the NIHAARP Diet and Health Study. Am J Epidemiol. 2008;168:38-48.

[34] O’Neil CE, Nicklas TA, Rampersaud GC, et al. One hundred percent orange juice consumption is associated with better diet quality, improved nutrient adequacy, and no increased risk for overweight/obesity in children. Nutr Res. 2011;31:673-682.

[35] US Department of Health and Human Services and USDA. Dietary Guidelines for Americans, 2010. 7th ed. Washington (DC): GPO; 2011.

[36] Ogden CL, Carroll MD, Kit BK, et al. Prevalence of childhood and adult obesity in the United States, 2011-2012. JAMA. 2014;311(8):806-814.

[37] U.S. Department of Health and Human Services. The Surgeon General's Vision for a Healthy and Fit Nation. Rockville, MD: U.S. Department of Health and Human Services, Office of the Surgeon General; 2010.

[38] Finkelstein EA, Trogdon JG, Cohen JW, et al. Annual medical spending attributable to obesity: payer- and servicespecific estimates. Health Affairs. 2009;28(5):w822-w831.

[39] Ridker PM, Wilson PW, Grundy SM. Should C-reactive protein be added to metabolic syndrome and to assessment of global cardiovascular risk? Circulation. 2004;109:2818-2825.

[40] Devaraj S, Singh U, Jialal I. Human C-reactive protein and the metabolic syndrome. Curr Opin Lipidol. 2009;20:182-189. 